\title{
Photochemistry and Evolution of Mars' Atmosphere: A Viking Perspective
}

\author{
Michael B. McElroy, Ten Ying Kong, AND Yuk Ling Yung \\ Center for Earth and Planetary Physics, Harvard University \\ Cambridge, Massachusetts 02138
}

\begin{abstract}
Viking measurements of the Martian upper atmosphere indicate thermospheric temperatures below $200^{\circ} \mathrm{K}$, temperatures much colder than those implied by remote sensing experiments on Mariner 6, 7, and 9 and Mars 3. The variability in thermospheric temperature may reflect an important dynamical coupling of upper and lower regions of the Martian atmosphere. Absorption of extreme ultraviolet solar radiation can account for observed features of the ionosphere and provides an important source of fast $\mathrm{N}$ and $\mathrm{O}$ atoms which may escape the planet's gravitational field. Isolopic measurements of oxygen and nitrogen impose useful constraints on models for planetary evolution. It appears that the abundance of $\mathrm{N}_{2}$ in Mars' past atmosphere may have exceeded the abundance of $\mathrm{CO}_{2}$ in the present atmosphere and that the planet also has copious sources of $\mathrm{H}_{2} \mathrm{O}$. The planet acquired its nitrogen atmosphere early in its history. The degassing rate for nitrogen in the present epoch must be less than the time-averaged degassing rate by at least a factor of 20 .
\end{abstract}

\section{INTRODUCTION}

The entry science experiments on Viking provide a wealth of new information on the structure and composition of Mars' upper atmosphere. They may be used, in combination with remote sensing data from earlier spacecraft, to develop a reasonably consistent model for Martian aeronomy.

It is clear that escape processes have played a major role in the evolution of Mars' atmosphere. Recombination of $\mathrm{O}_{2}{ }^{+}$in the planetary exosphere provides a significant source for fast atoms which can escape the planet's gravitational field. Compositional data inferred from the retarding potential analyzer experiment [Nier et al., 1976b; W. B. Hanson, private communication, 1977] indicate that $\mathrm{O}_{2}{ }^{+}$is the major constituent of the Martian ionosphere and suggest an average escape rate of about $6 \times 10^{7}$ oxygen atoms $\mathrm{cm}^{-2} \mathrm{~s}^{-1}$. The chemistry of the bulk atmosphere is regulated by oxygen escape on a time scale of the order of $10^{3}$ years in such a manner as to ensure an escape rate for $\mathrm{H}$ atoms of the magnitude of $1.2 \times 10^{8}$ atoms $\mathrm{cm}^{-2} \mathrm{~s}^{-1}$. Hydrogen molecules are formed in the lower atmosphere by reaction of $\mathrm{H}$ with $\mathrm{HO}_{2}$. Escaping $\mathrm{H}$ atoms are released by ionospheric reactions involving $\mathrm{H}_{2}$ and $\mathrm{CO}_{2}{ }^{+}$.

Models for the Martian ionosphere are developed in section 2 and are shown to agree satisfactorily with in situ measurements by Viking. The upper atmosphere measured by Viking is unusually cold. The scale height of $\mathrm{CO}_{2}$ is about $8 \mathrm{~km}$, which may be compared with scale heights in the range $15-22 \mathrm{~km}$ as inferred from the ultraviolet spectrometer experiment on Mariner 9 [Stewart et al., 1972]. It is clear that the temperature of Mars' upper atmosphere is quite variable, ranging from as low as $120^{\circ} \mathrm{K}$ to perhaps as high as $400^{\circ} \mathrm{K}$. This variability may be seen also in the topside plasma scale heights as measured by Mariner 4 [Kliore et al., 1965], Mariner 6 and 7 [Kliore et al., 1969; Fjeldbo et al., 1970], and Mariner 9 [Kliore, 1974]. The general characteristics of the ionosphere may be reproduced by a relatively simple photochemical model if proper account is taken of the variability of the extreme ultraviolet solar flux. It is unlikely, however, that such a simple model can account for the observed variation in atmospheric temperature.

The photochemistry of Mars' atmosphere is discussed in section 3. In accord with earlier models [Parkinson and Hunten, 1972; McElroy and Donahue, 1972; Liu and Donahue, 1976; Kong and McElroy, 1977a,b] we assume that photolysis of $\mathrm{CO}_{2}$ is balanced mainly by gas phase reaction of $\mathrm{CO}$ with $\mathrm{OH}$. Models are constrained to agree with recent measurements (B. A. Thrush, private communication to R. T. Watson, 1977) of the rate constant for reaction of $\mathrm{OH}$ with $\mathrm{HO}_{2}$ and are adjusted to provide a hydrogen escape flux of $1.2 \times 10^{8}$ atoms $\mathrm{cm}^{-2} \mathrm{~s}^{-1}$ in agreement with fluxes measured by Mariner 9 [Barth et al., 1972]. Results are developed to illustrate possible variations in upper atmospheric composition over a Martian year.

Measurements of the isotopic composition of oxygen and nitrogen may be used to place important constraints on the evolution of Mars' atmosphere. The observed enrichment of ${ }^{15} \mathrm{~N}$ relative to ${ }^{14} \mathrm{~N}$ for Mars' atmosphere as compared to that of the earth implies that Mars had 'a much larger nitrogen atmosphere in the past. In a similar manner the lack of a detectable enrichment of the isotopic ratio ${ }^{18} \mathrm{O} /{ }^{16} \mathrm{O}$ in Mars' atmosphere may be taken to imply significant exchange between the atmosphere and an extensive surface or subsurface reservoir containing a volatile form of oxygen, most probably $\mathrm{H}_{2} \mathrm{O}$. Measurements of noble gases in Mars' atmosphere [Owen and Biemann, 1976; Owen et al., 1976] pose additional constraints on planetary evolution, and the implications of these data are explored in section 4.

\section{IONOSPHERIC ChEMISTRY AND STRUCTURE}

Carbon dioxide is the major constituent of Mars' atmosphere over the ionospherically important height range 120-180 km [Nier et al., 1976b; Nier and McElroy, 1976, 1977]. Electrons are produced mainly by photo-ionization of $\mathrm{CO}_{2}$ :

$$
h \nu+\mathrm{CO}_{2} \rightarrow \mathrm{CO}_{2}^{+}+e
$$

The primary photo-ion, $\mathrm{CO}_{2}{ }^{+}$, may be removed either by dissociative recombination,

$$
\mathrm{CO}_{2}{ }^{+}+e-\mathrm{CO}+\mathrm{O}
$$

or by reaction with O [Stewart, 1972; McElroy and McConnell, 1971; Fehsenfeld et al., 1970],

$$
\mathrm{CO}_{2}^{+}+\mathrm{O} \rightarrow \mathrm{O}_{2}^{+}+\mathrm{CO}
$$




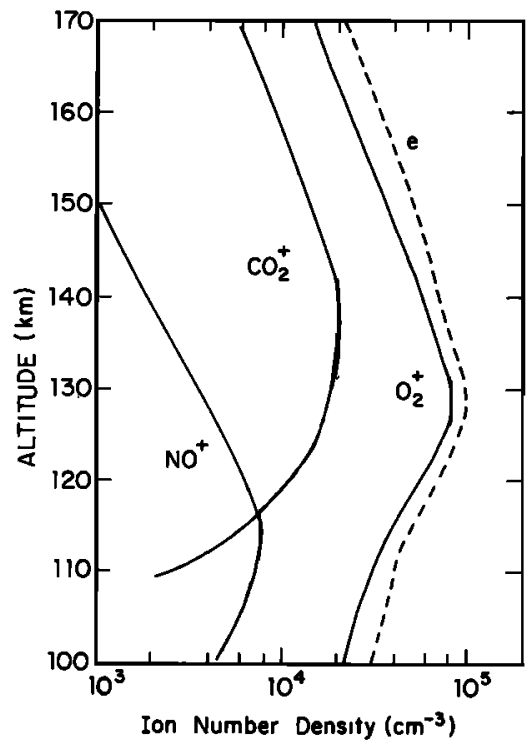

Fig. 1. Number densities for the Martian ionosphere. Results were obtained by using densities for neutral species measured by Viking 1 [Nier and McElroy, 1976, 1977]. Corresponding ionospheric reactions are given in Table !.

Reaction (3) ensures that $\mathrm{O}_{2}{ }^{+}$should be the dominant component of Mars' ionosphere at all heights below about $300 \mathrm{~km}$.

A model ionosphere derived by using densities for neutral species measured by Viking 1 [Nier and McElroy, 1976, 1977] is shown in Figure 1. A summary of important reactions and relevant rate constants is given in Table 1 . Values for the flux of sunlight at extreme ultraviolet wavelengths were taken from a paper by Hinteregger [1976] and reflect recent measurements by the Atmosphere Explorer aeronomy satellites.

The Viking measurements were taken during a period of exceptionally low solar activity. The solar flux at $10.7 \mathrm{~cm}$ had a value of $69.4 \times 10^{-22} \mathrm{~W} \mathrm{~m}^{-2} \mathrm{~Hz}^{-1}$ at I AU on July 20,1976 , which may be compared with a flux of $75.7 \times 10^{-22} \mathrm{~W} \mathrm{~m}^{-2}$ $\mathrm{Hz}^{-1}$ at $1 \mathrm{AU}$ on September 3, 1976, during the entry of Viking 2 , and fluxes in the range (110-145) $\times 10^{-22} \mathrm{~W} \mathrm{~m}^{-2} \mathrm{~Hz}^{-1}$ for the Mariner 9 standard mission (November 14 to December $23,1971)$ or $(110-169) \times 10^{-22} \mathrm{~W} \mathrm{~m}^{-2} \mathrm{~Hz}^{-1}$ during the ex-

TABLE 1. Important Ionospheric Reactions in the Martian Ionosphere

\begin{tabular}{|c|c|}
\hline Reaction & Rate Coefficient \\
\hline $\begin{array}{l}\mathrm{CO}_{2}+h \nu \rightarrow \mathrm{CO}_{2}^{+}+e \\
\mathrm{~N}_{2}+h \nu \rightarrow \mathrm{N}_{2}^{+}+e \\
\mathrm{O}+h \nu \rightarrow \mathrm{O}^{+}+e \\
\mathrm{CO}+h \nu \rightarrow \mathrm{CO}^{+}+e \\
\mathrm{CO}_{2}^{+}+\mathrm{O} \rightarrow \mathrm{CO}+\mathrm{O}_{2}^{+} \\
\mathrm{CO}_{2}^{+}+\mathrm{O} \rightarrow \mathrm{CO}_{2}+\mathrm{O}^{+} \\
\mathrm{N}_{2}^{+}+\mathrm{CO}_{2} \rightarrow \mathrm{N}_{2}+\mathrm{CO}_{2}^{+} \\
\mathrm{O}^{+}+\mathrm{CO}_{2} \rightarrow \mathrm{CO}+\mathrm{O}_{2}^{+} \\
\mathrm{CO}^{+}+\mathrm{CO}_{2} \rightarrow \mathrm{CO}+\mathrm{CO}_{2}^{+} \\
\mathrm{CO}_{2}^{+}+\mathrm{NO} \rightarrow \mathrm{CO}+\mathrm{NO}^{+} \\
\mathrm{O}_{2}^{+}+\mathrm{NO} \rightarrow \mathrm{O}_{2}+\mathrm{NO}^{+} \\
\mathrm{CO}_{2}^{+}+e \rightarrow \mathrm{CO}+\mathrm{O} \\
\mathrm{O}_{2}^{+}+e \rightarrow \mathrm{O}+\mathrm{O} \\
\mathrm{NO}^{+}+e \rightarrow \mathrm{N}+\mathrm{O}\end{array}$ & $\begin{aligned} J_{1} & =2.4 \times 10^{-7} \\
J_{2} & =8.7 \times 10^{-8} \\
J_{3} & =1.2 \times 10^{-7} \\
J_{4} & =4.4 \times 10^{-7} \\
k_{1} & =1.6 \times 10^{-10} \\
k_{2} & =1.0 \times 10^{-10} \\
k_{3} & =9 \times 10^{-10} \\
k_{5} & =1 \times 10^{-8} \\
k_{8} & =1 \times 10^{-\theta} \\
k_{7} & =1.2 \times 10^{-10} \\
k_{\mathrm{B}} & =6.3 \times 10^{-10} \\
k_{\mathrm{B}} & =3.8 \times 10^{-7} \\
k_{10} & =2.2 \times 10^{-7}\left(300 / T_{e}\right) \\
k_{11} & =4.3 \times 10^{-7}\left(300 / T_{e}\right)^{0.37}\end{aligned}$ \\
\hline
\end{tabular}

$T_{e}$ denotes electron temperature, taken to be equal to the value for neutral temperature in the present study. Photodissociation rates $(J)$ at the top of the atmosphere are given in reciprocal seconds. Twobody reaction rates $(k)$ are in cubic centimeters per second. This table is taken from McElroy et al. [1976]. tended mission I (May 7 to June 25, 1972). A limited number of computations were carried out under conditions appropriate for Mariner 9. For the extended mission I in 1972 a Vikinglike thermal structure was used for the middle and lower portions of Mars' atmosphere. For the standard mission a considerably warmer atmosphere was assumed (for altitudes below $100 \mathrm{~km}$ ) in order to account for the large amount of dust present in the atmosphere at that time [Kliore et al., 1972]. If one defines an effective temperature $T_{\text {eff }}$ given by

$$
T_{\text {erf }}=Z_{m}\left(\int_{0}^{Z_{m}} \frac{d z}{T}\right)^{-1}
$$

for the atmosphere below the ionospheric peak $Z_{m}$, then the effective temperature ( $T_{\text {efr }}$ ) for the standard mission is about $20^{\circ} \mathrm{K}$ warmer than the value assumed for the first extended mission.

An excellent fit to the Mariner data may be obtained if the EUV flux is assumed to vary according to the relation

$$
F_{\mathrm{EUV}} \quad 0.0222 F_{\mathrm{EUV}}{ }^{0}\left(F_{10.7}-25\right) / R^{2}
$$

( $F_{\mathrm{EUv}}{ }^{0}$ is the solar EUV flux taken from Hinteregger [1976], and $R$ (in astronomical units) denotes the planet's radial distance from the sun) and if upper atmospheric temperatures are fixed by using plasma scale heights reported by Kliore et al. [1973]. Calculated values for peak electron density are compared with observations in Figure 2. Estimated values for the height of the ionospheric maximum are compared with observations in Figure 3. The variation of EUV flux with solar activity implied by (4) is somewhat larger than the range of intensities observed for dayglow emission in the Cameron bands of CO [Stewart et al., 1972] and is also larger than variations observed by Hinteregger [1970] for the chromospheric EUV emission lines at 1025, 977, 630, 584, and $304 \AA$. The discrepancy may not be serious, however. It may reflect the role of high-excitation solar lines (for example, lines from Fe XV and Fe XVI) and differences in spectral regions important for photo-ionization and excitation of Cameron bands in the Martian atmosphere. We may note that the trend with zenith angle for both peak electron density and peak ionospheric height during the extended mission I is satisfactorily described by the model. Interpretation of the variation of peak

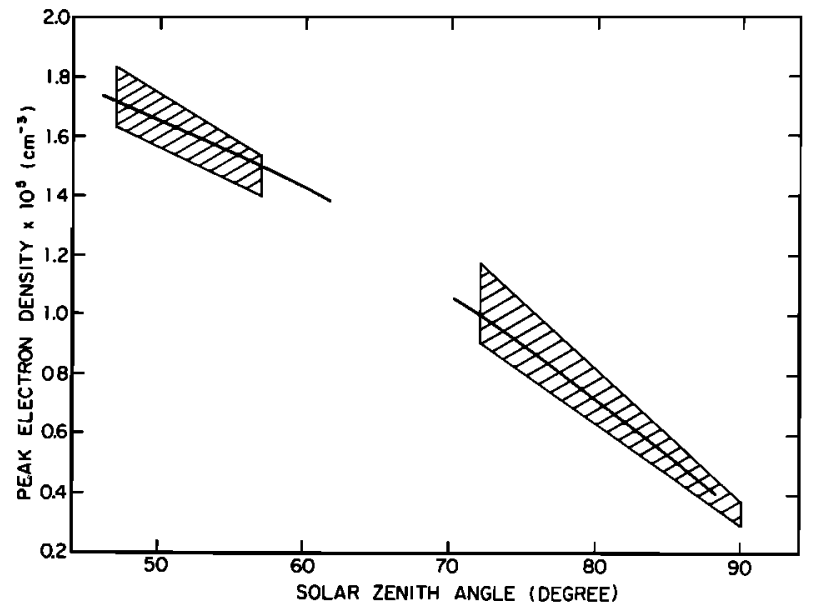

Fig. 2. Peak electron density in the Martian ionosphere versus solar zenith angle. Shaded regions represent data obtained by the Mariner 9 radio occultation experiment during its standard mission $\left(47^{\circ}-57^{\circ}\right)$ and extended mission I $\left(>72^{\circ}\right)$ [Kliore et al., 1973]. Solid curves are densities from theoretical computations as described in the text. Solar EUV flux was assumed to vary with $F_{10.7}$, and $R$ according to (4). 
altitude with zenith angle during the standard mission is complicated because of temporal variations in the structure of the lower atmosphere which occurred during this period. Mariner 9 arrived at Mars when the planet was enveloped by a global dust storm [Kliore et al., 1972]. The solid curve for the standard mission in Figure 3 assumes that the effective temperature was $20^{\circ} \mathrm{K}$ warmer than values applicable for the extended mission. The trend of peak altitude with zenith angle differs significantly from the observed trend. We believe, however, that the discrepancy may be attributed to a gradual clearing of dust accompanied by steady cooling of the lower atmosphere. If we assume that the effective temperature declined by $8^{\circ} \mathrm{K}$ over the first 6 weeks of the Mariner mission, we obtain the trend indicated by the dashed line in Figure 3, a result evidently consistent with observation [Conrath, 1975]. The comparisons shown in Figures 2 and 3 indicate that solar EUV radiation may provide the dominant source of ionization for Mars.

It is more difficult to account for the range of values inferred for thermospheric temperature. The intensity of the CO Cameron band emission is nicely correlated with observed variations in the $10.7-\mathrm{cm}$ solar flux. In contrast, the scale height of the Cameron bands exhibits no such correlation [Stewart et al., 1972]. There can be little doubt, however, that the thermospheric temperature varies considerably with time. Figure 4 summarizes the available information, including data from Mariner 4, 6, 7, and 9 [Kliore et al., 1965, 1969; Fjeldbo et al., 1970; D. E. Anderson and C. W. Hord, 1971; Kliore, 1974; Stewart et al., 1972], Mars 3 [Izakov, 1973], and Viking 1 and 2 [Nier and McElroy, 1976; McElroy et al., 1976]. The lowest temperatures were observed for Viking 1 and 2 and Mariner 4. Noting the absence of a correlation of airglow scale height with solar activity, at least over short time periods on Mariner 9, one is tempted to postulate that the temperature of Mars' upper atmosphere may be affected to a considerable extent by processes originating in the lower atmosphere [Stewart et al., 1972]. The Viking data indicate that gravity waves excited in the lower atmosphere may propagate to high altitudes on Mars [McElroy et al., 1976]. These waves may deliver significant amounts of energy to the upper atmosphere and may be responsible, at least in part, for the high-altitude mixing detected by Viking [McElroy et al., 1976; Nier and McElroy, 1977]. Excitation of these waves should be favored when Mars is closest to the sun and may be enhanced further by the additional aerosol burden known to be present in the air at that time [Gierasch and Goody, 1972]. Further data are clearly required in order to resolve this issue. It must be pointed out, however, that the data in Figure 4 could also be used to argue a gross correlation of thermospheric temperature with solar activity. It would be difficult, though, to account for the range of temperatures exhibited in Figure 4 if EUV solar radiation should be the only important thermospheric heat source [see Stewart et al., 1972].

\section{Photochemistry}

The chemistry of the bulk Martian atmosphere should be relatively insensitive to short-period changes in the temperature of the upper atmosphere. Carbon monoxide, formed by photodissociation of $\mathrm{CO}_{2}$, has a time constant of about 3 years, and a somewhat longer time constant applies for $\mathrm{O}_{2}$, formed mainly by

$$
\mathrm{O}+\mathrm{OH} \rightarrow \mathrm{O}_{2}+\mathrm{H}
$$

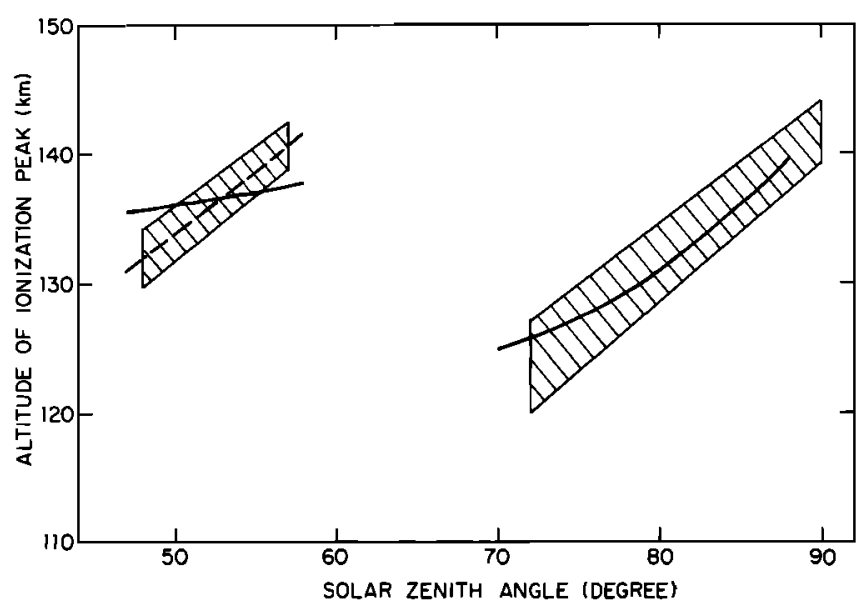

Fig. 3. Altitude of the ionospheric maximum (above a 3-mbar pressure level) versus solar zenith angle. Notation and conditions are the same as those in Figure 2. The solid curve for the standard mission assumes that the effective temperature $T_{\text {err }}$ was $20^{\circ} \mathrm{K}$ warmer than the value applicable for the extended mission. The dashed curve assumes that the effective temperature declined by $8^{\circ} \mathrm{K}$ over the first 6 weeks of the Mariner 9 mission.

Molecular hydrogen, produced by

$$
\mathrm{H}+\mathrm{HO}_{2} \rightarrow \mathrm{H}_{2}+\mathrm{O}_{2}
$$

has a time constant of approximately $10^{3}$ years. We shall assume that the chemistry of the bulk atmosphere may be adequately described by using the average model given in Figure 5.

Reactions important for a carbon-hydrogen-oxygen atmosphere are summarized in Table 2 . Odd hydrogen compounds are supplied by photochemical decomposition of $\mathrm{H}_{2} \mathrm{O}$, either by photolysis,

$$
h v+\mathrm{H}_{2} \mathrm{O} \rightarrow \mathrm{OH}+\mathrm{H}
$$

or by reaction with $\mathrm{O}\left({ }^{1} D\right)$,

$$
\mathrm{O}\left({ }^{1} D\right)+\mathrm{H}_{2} \mathrm{O} \rightarrow \mathrm{OH}+\mathrm{OH}
$$

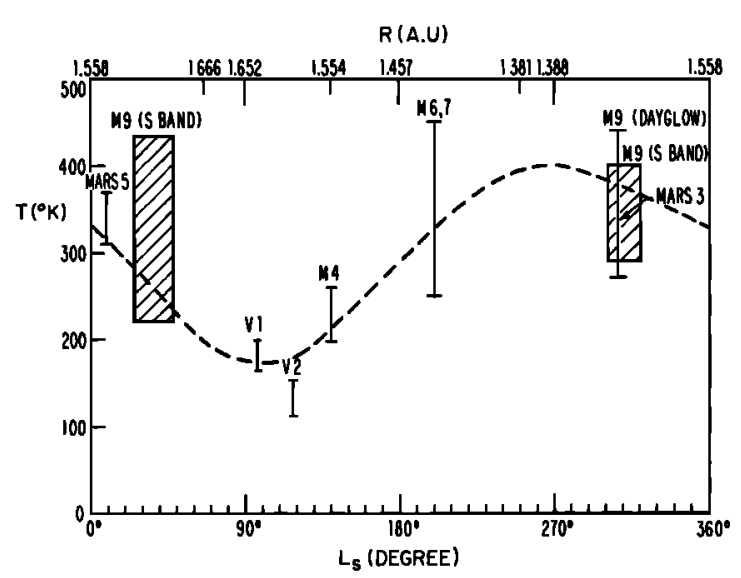

Fig. 4. Temperature of Mars' upper atmosphere obtained during the missions of Mariner 4, 6, 7, and 9, Mars 3 and 5, and Viking 1 and 2. Data (each uncertainty being indicated by an error bar) are plotted against the planetocentric solar longitude of Mars, $L_{s}$, and the radial distance from the sun, $R$, during the period of each mission. Shaded regions represent temperatures derived from topside plasma scale heights obtained by the Mariner 9 radio occultation experiment [Kliore et al., 1973]. Dashed curve indicates a possible seasonal variation for temperature in the Martian upper atmosphere. 


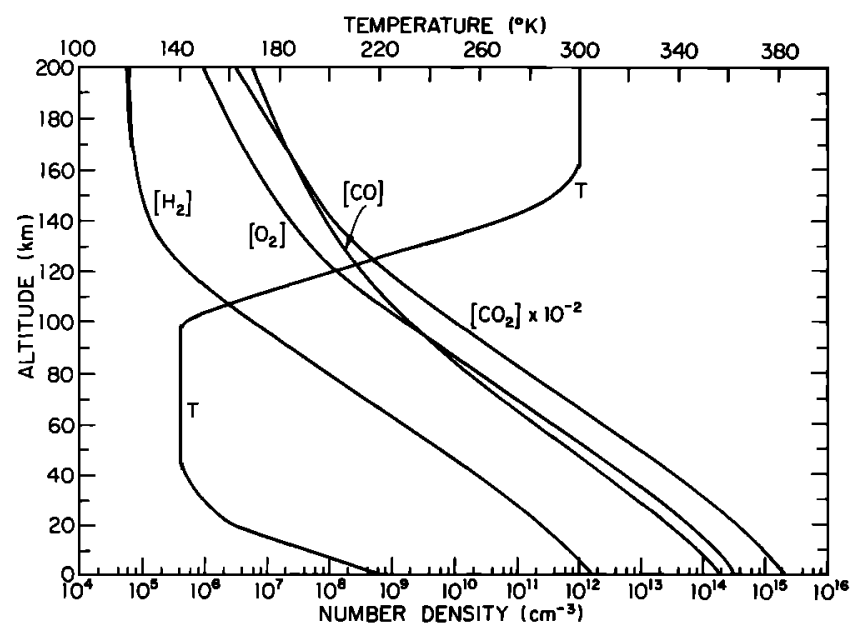

Fig. 5. Time-averaged model for the Martian atmosphere.

Water may be reformed by

$$
\mathrm{OH}+\mathrm{HO}_{2} \rightarrow \mathrm{H}_{2} \mathrm{O}+\mathrm{O}_{2}
$$

There is, however, a small net sink for $\mathrm{H}_{2} \mathrm{O}$ at low altitudes associated with formation of $\mathrm{H}_{2}$ by reaction (6). Hydrogen is transported upward and escapes mainly in atomic form, atoms being released by reaction of $\mathrm{CO}_{2}{ }^{+}$with $\mathrm{H}_{2}$ :

$$
\mathrm{CO}_{2}^{+}+\mathrm{H}_{2} \rightarrow \mathrm{CO}_{2} \mathrm{H}^{+}+\mathrm{H}
$$

followed by

$$
\mathrm{CO}_{2} \mathrm{H}^{+}+e \rightarrow \mathrm{CO}_{2}+\mathrm{H}
$$

Hydrogen escape is limited by the supply of $\mathrm{H}_{2}$ from below. Production of $\mathrm{H}_{2}$ is determined by $(6)$ and is limited by the abundance of tropospheric $\mathrm{H}$ atoms. The abundance of tropospheric $\mathrm{H}$ is set by balance between

$$
\mathrm{CO}+\mathrm{OH} \rightarrow \mathrm{CO}_{2}+\mathrm{H}
$$

and

$$
\mathrm{H}+\mathrm{O}_{2}+\mathrm{CO}_{2} \rightarrow \mathrm{HO}_{2}+\mathrm{CO}_{2}
$$

and is therefore sensitive to the net oxidation state of the atmosphere. The oxidation state of the atmosphere is determined by the relative magnitude of $\mathrm{H}$ and $\mathrm{O}$ escape rates. The escape rates are regulated at the present epoch [McElroy, 1972; McElroy and Donahue, 1972; McElroy and Kong, 1976] to ensure a relatively steady oxidation state, $\mathrm{H}$ atoms being transported upward as $\mathrm{H}_{2}$ and $\mathrm{O}$ atoms being supplied to the exosphere mainly as components of upward flowing $\mathrm{CO}_{2}$. The hydrogen escape rate is set ultimately by the rate at which oxygen escapes. The escape rate for $O$ is set by the rate at which $\mathrm{CO}_{2}$ is photo-ionized in the exosphere and should maintain a relatively steady value over large intervals of geologic time. At the present epoch, water evaporates from the surface, is processed photochemically by the atmosphere, and escapes to space at a steady rate of $6 \times 10^{7}$ molecules $\mathrm{cm}^{-2} \mathrm{~s}^{-1}$. If this rate had applied over the past $4.5 \times 10^{9}$ years, Mars would have lost to space an amount of $\mathrm{H}_{2} \mathrm{O}$ sufficient to coat the surface of the planet with ice to an average depth of about 2.5 $m$. It should be emphasized, however, that the net quantity of $\mathrm{H}_{2} \mathrm{O}$ processed by the planet could significantly exceed this figure if heterogeneous reactions at the planetary surface might be shown to represent a sink for $\mathrm{O}$ of a magnitude comparable to or larger than that due to escape [e.g., Huguenin, 1973a, $b$, 1974, 1976].

\begin{tabular}{|c|c|c|}
\hline $\begin{array}{c}\text { Reaction } \\
\text { No. }\end{array}$ & Reaction & Rate Expression \\
\hline $\begin{array}{l}(1) \\
(2) \\
(3) \\
(4) \\
(5) \\
(6) \\
(7) \\
(8) \\
(9) \\
(10) \\
(11) \\
(12) \\
(13 a) \\
(13 b) \\
(14) \\
(15) \\
(16) \\
(17) \\
(18) \\
(19) \\
(20) \\
(21) \\
(22)\end{array}$ & $\begin{array}{l}h \nu+\mathrm{CO}_{2} \rightarrow \mathrm{CO}+\mathrm{O} \\
\left.\mathrm{CO}+\mathrm{O}^{3} P\right)+\mathrm{CO}_{2} \rightarrow \mathrm{CO}_{2}+\mathrm{CO}_{2} \\
\mathrm{CO}+\mathrm{OH} \rightarrow \mathrm{CO}_{2}+\mathrm{H} \\
\mathrm{H}+\mathrm{O}_{2}+\mathrm{CO}_{2} \rightarrow \mathrm{HO}_{2}+\mathrm{CO}_{2} \\
\mathrm{O}+\mathrm{HO}_{2} \rightarrow \mathrm{OH}+\mathrm{O}_{2} \\
\mathrm{O}+\mathrm{O}+\mathrm{CO}_{2} \rightarrow \mathrm{O}_{2}+\mathrm{CO}_{2} \\
\mathrm{HO}_{2}+\mathrm{HO}_{2} \rightarrow \mathrm{H}_{2} \mathrm{O}_{2}+\mathrm{O}_{2} \\
h \nu+\mathrm{H}_{2} \mathrm{O}_{2} \rightarrow \mathrm{OH}+\mathrm{OH} \\
\mathrm{O}+\mathrm{OH} \rightarrow \mathrm{O}_{2}+\mathrm{H} \\
h \nu+\mathrm{H}_{2} \mathrm{O} \rightarrow \mathrm{OH}+\mathrm{H} \\
\mathrm{O}\left({ }^{1} D\right)+\mathrm{H}_{2} \mathrm{O} \rightarrow \mathrm{OH}+\mathrm{OH} \\
\mathrm{O}\left({ }^{1} D\right)+\mathrm{H}_{2} \rightarrow \mathrm{OH}+\mathrm{H} \\
h \nu+\mathrm{O}_{3} \rightarrow \mathrm{O}_{2}\left({ }^{1} \Delta_{g}\right)+\mathrm{O}\left({ }^{1} D\right) \\
\left.h \nu+\mathrm{O}_{3} \rightarrow \mathrm{O}_{2}+\mathrm{O}^{3} P\right) \\
\mathrm{OH}+\mathrm{HO}_{2} \rightarrow \mathrm{H}_{2} \mathrm{O}+\mathrm{O}_{2} \\
\mathrm{H}+\mathrm{HO}_{2} \rightarrow \mathrm{H}_{2}+\mathrm{O}_{2} \\
h \nu+\mathrm{O}_{2} \rightarrow \mathrm{O}+\mathrm{O} \\
\mathrm{O}+\mathrm{O}_{2}+\mathrm{CO}_{2} \rightarrow \mathrm{O}_{3}+\mathrm{CO}_{2} \\
\mathrm{O}+\mathrm{O}_{3} \rightarrow \mathrm{O}_{2}+\mathrm{O}_{2} \\
\mathrm{H}+\mathrm{O}_{\mathrm{a}} \rightarrow \mathrm{OH}^{3}+\mathrm{O}_{2} \\
\left.\mathrm{O}\left({ }^{1} D\right)+\mathrm{CO}_{2} \rightarrow \mathrm{O}^{3} P\right)+\mathrm{CO}_{2} \\
\mathrm{O}_{2}\left({ }^{1} \Delta_{g}\right) \rightarrow \mathrm{O}_{2}\left({ }^{3} \Sigma_{\mathrm{g}}-\right)+h \nu \\
\mathrm{O}_{2}\left({ }^{1} \Delta_{\mathrm{g}}\right)+\mathrm{CO}_{2} \rightarrow \mathrm{O}_{2}\left({ }^{3} \Sigma_{g}{ }^{-}\right)+\mathrm{CO}_{2}\end{array}$ & 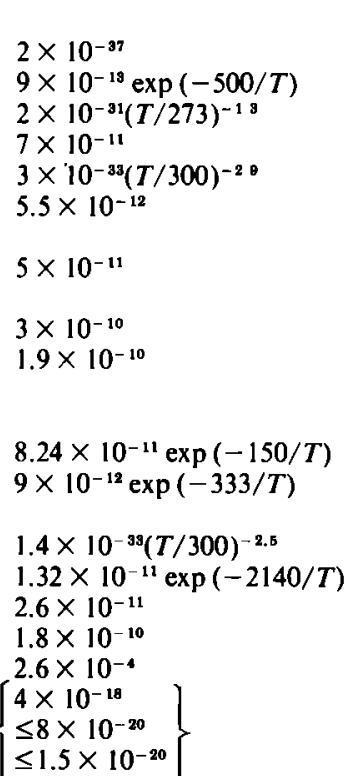 \\
\hline
\end{tabular}

Densities for $\mathrm{H}, \mathrm{OH}, \mathrm{HO}_{2}, \mathrm{H}_{2} \mathrm{O}_{2}, \mathrm{O}$, and $\mathrm{O}_{3}$ as calculated for Mars' atmosphere are given in Figure 6. Computational details are described by Kong and McElroy [1977a]. Rates for

TABLE 2. Chemical Reactions in the Neutral Martian Atmosphere

Units for rate constants are $\mathrm{s}^{-1}$ for unimolecular reactions, $\mathrm{cm}^{3} \mathrm{~s}^{-1}$ for bimolecular reactions, and $\mathrm{cm}^{6}$ $\mathrm{s}^{-1}$ for termolecular reactions. Photodissociation rates $\left(\mathrm{s}^{-1}\right)$ are calculated from solar flux and relevant cross-section data. Rate for reaction (14) is taken from the recent measurement by Thrush [1977], and the references for the rest of the reactions are given by Kong and McElroy [1977a]. 


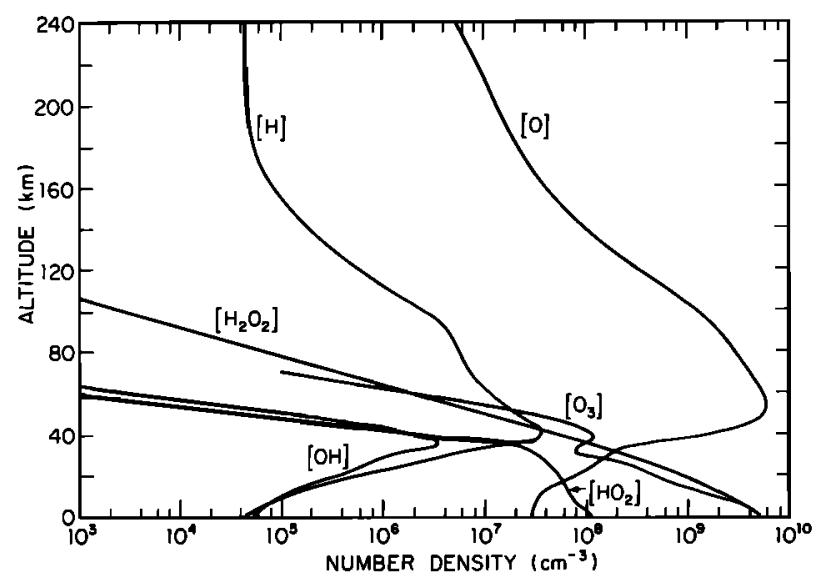

Fig. 6. Density distributions of $\mathrm{H}, \mathrm{OH}, \mathrm{HO}_{2}, \mathrm{H}_{2} \mathrm{O}_{2}, \mathrm{O}$, and $\mathrm{O}_{3}$ in the Mars atmosphere. Results were obtained by using the averaged model atmosphere given in Figure 5. Surface was assumed to be inert, and mean water vapor abundance in the atmosphere was taken to be 10 precipitable $\mu \mathrm{m}$.

reactions contributing to the budget of odd hydrogen are illustrated as functions of altitude in Figure 7. Sources and sinks for $\mathrm{CO}_{2}$ and $\mathrm{O}_{2}$ are summarized in Figures 8 and 9, and the variation of upper atmospheric $\mathrm{H}$ and $\mathrm{H}_{2}$ with exospheric temperature is illustrated by Figure 10.

It may be of interest to consider the response of the atmosphere to a large transient source for $\mathrm{H}_{2} \mathrm{O}$, which might arise, for example, during periods of active volcanism. An injection of $\mathrm{H}_{2} \mathrm{O}$ at high altitudes could lead to a significant source for $\mathrm{H}_{2}$, formed directly by photodissociation at wavelengths near Lyman $\alpha$. The source strength could be as large as $5 \times 10^{10}$ molecules $\mathrm{cm}^{-2} \mathrm{~s}^{-1}$. Hydrogen formed in this manner could escape readily to space, leaving oxygen in the atmosphere in concentrations sufficient perhaps even to perturb the total atmospheric pressure. Mars could acquire a relatively long lived transient atmosphere with $\mathrm{O}_{2}$ as a major constituent. This atmosphere would relax by escape. The associated relaxation time could be relatively long, however, since the $O$ escape rate cannot exceed the value noted earlier, $6 \times 10^{7}$ atoms $\mathrm{cm}^{-2}$ $\mathrm{s}^{-1}$

The chemistry of a nitrogen-hydrogen-oxygen-carbon system was investigated recently by Yung et al. [1977]. Nitric oxide is formed in the upper atmosphere by reaction of $\mathrm{N}\left({ }^{2} D\right)$ with $\mathrm{CO}_{2}$,

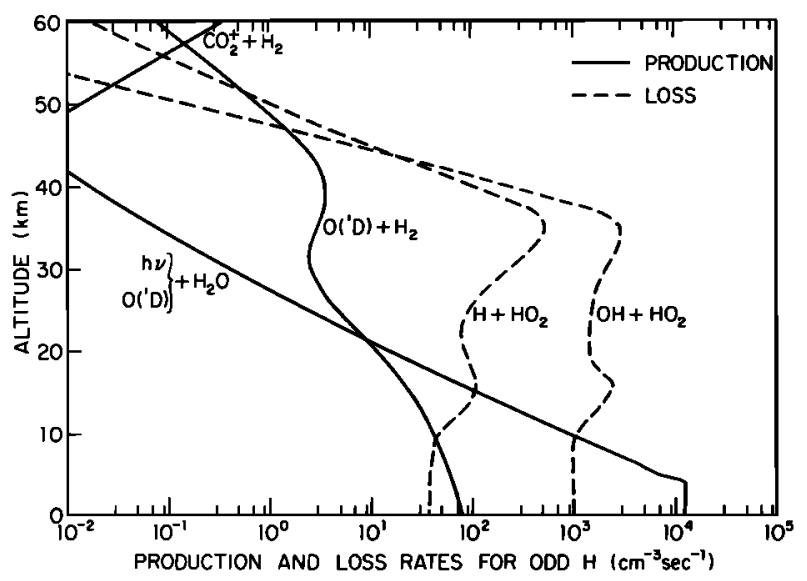

Fig. 7. Production and loss rates for odd $\mathrm{H}$ in the lower Martian atmosphere (conditions are the same as those in Figure 6).

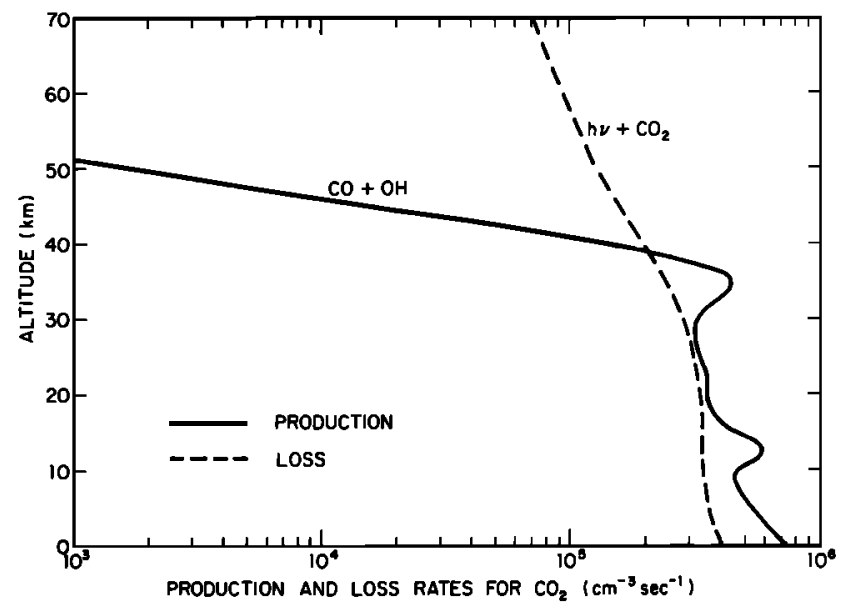

Fig. 8. Production and loss rates for $\mathrm{CO}$ in the Martian atmosphere (conditions are the same as those in Figure 6).

$$
\mathrm{N}\left({ }^{2} D\right)+\mathrm{CO}_{2} \rightarrow \mathrm{NO}+\mathrm{CO}
$$

and is removed mainly by

$$
\mathrm{N}\left({ }^{4} S\right)+\mathrm{NO} \rightarrow \mathrm{N}_{2}+\mathrm{O}
$$

Odd nitrogen atoms are released by ionospheric reactions and by electron impact dissociation of $\mathrm{N}_{2}$. A relatively simple model gives results in satisfactory accord with measurements of upper atmospheric NO reported by Nier et al. [1976a]. Results are shown in Figure 11, which includes several theoretical curves which differ mainly in assumptions made with regard to the yield of $N\left({ }^{2} D\right)$ in electron impact dissociation of $\mathrm{N}_{2}$ [McElroy et al., 1976]. Densities for major forms of odd nitrogen in the lower atmosphere are shown [after Yung et al., 1977] in Figure 12. Densities computed for the lower atmosphere are sensitive to assumptions made with regard to the role of surface chemistry. We assumed that $\mathrm{HNO}_{2}$ and $\mathrm{HNO}_{3}$ could be incorporated in surface minerals at rates (molecules $\mathrm{cm}^{-2} \mathrm{~s}^{-1}$ ) given by $\gamma n v$, where $\gamma$ denotes an activity coefficient, $n$ indicates the density $\left(\mathrm{cm}^{-3}\right)$ of $\mathrm{HNO}_{2}+\mathrm{HNO}_{3}$, and $v$ is an appropriate thermal velocity $\left(\mathrm{cm} \mathrm{s}^{-1}\right.$ ). The results in Figure 12 were derived with $\gamma$ set equal to $10^{-2}$.

\section{Models for Planetary Evolution}

Measurements of isotopic composition may be used to impose important constraints on the range of permissible models

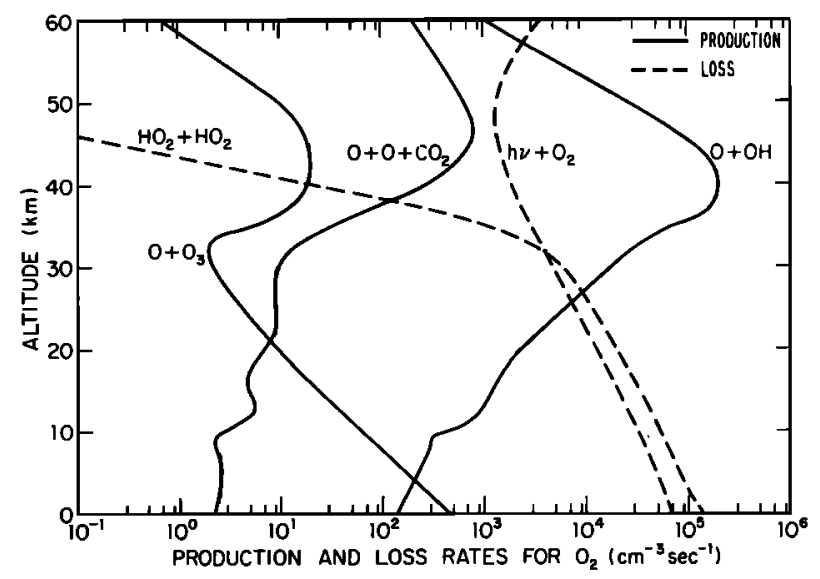

Fig. 9. Production and loss rates for $\mathrm{O}_{2}$ in the Martian atmosphere (conditions are the same as those in Figure 6). 


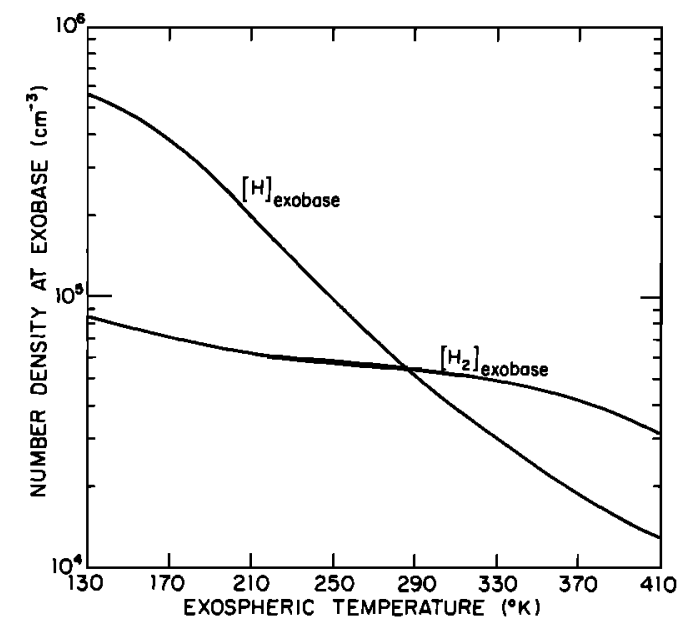

Fig. 10. Density variations of $\mathrm{H}$ and $\mathrm{H}_{2}$ at critical level versus exospheric temperature. Ionospheric structure was assumed to be fixed in the present model.

for planetary evolution. Mars has lost significant amounts of oxygen and nitrogen over geologic time. Oxygen escape proceeds by production of fast atoms in the exosphere, atoms being formed primarily by the sequence, reaction (3), or

$$
\mathrm{O}^{+}+\mathrm{CO}_{2} \rightarrow \mathrm{O}_{2}^{+}+\mathrm{CO}
$$

followed by

$$
\mathrm{O}_{2}^{+}+e \rightarrow \mathrm{O}+\mathrm{O}
$$

Nitrogen atoms with sufficient velocity for escape may be formed by

$$
e+\mathrm{N}_{2} \rightarrow e+\mathrm{N}+\mathrm{N}
$$

and

$$
e+\mathrm{N}_{2}^{+} \rightarrow \mathrm{N}+\mathrm{N}
$$

and we may note that these reactions are sufficiently energetic that they should proceed with equal efficiency for all oxygen

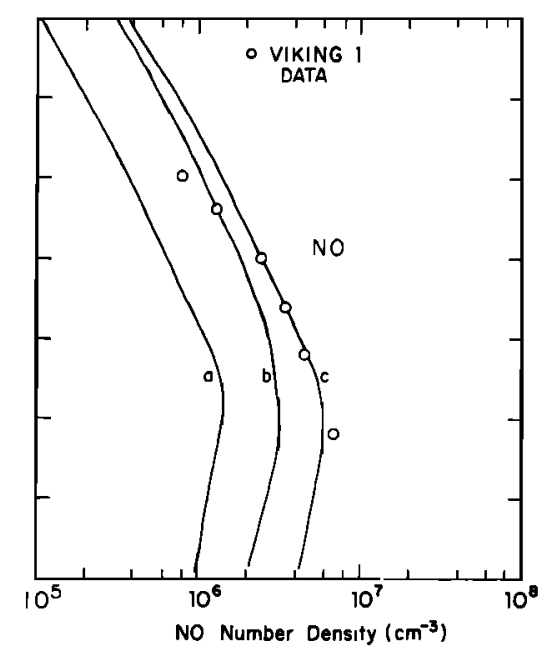

Fig. 11. Comparison of computed and measured number densities of NO in the upper atmosphere of Mars. Curve $a$ is obtained by using cross sections for electron impact dissociation of $\mathrm{N}_{2}$ as measured by Winters with a quantum yield for $\mathrm{N}\left({ }^{2} D\right)$ set equal to $50 \%$. Curves $b$ and $c$ allow for uncertainties in Winters' cross sections at low energy and in the quantum yield for $\mathrm{N}\left({ }^{2} D\right)$, as described in more detail by McElroy et al. [1976].

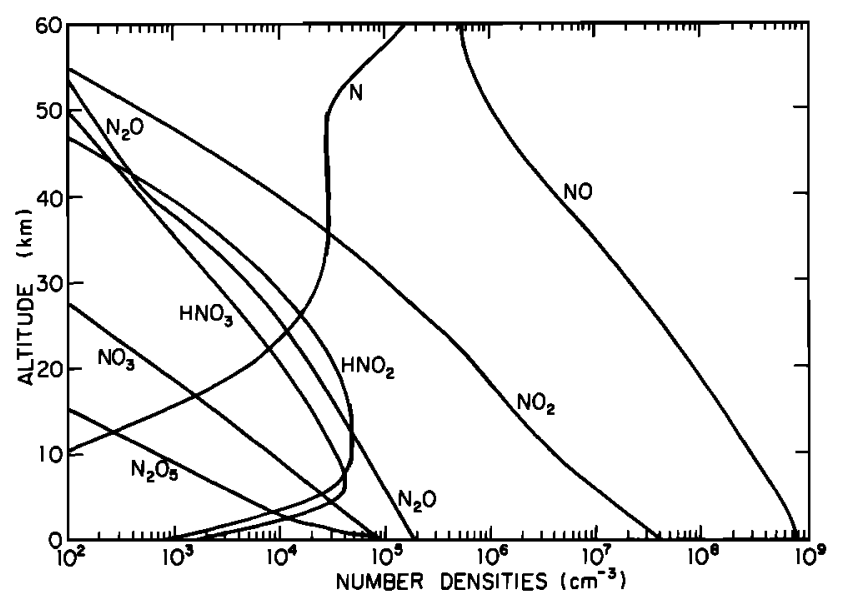

Fig. 12. Number densities of $\mathrm{N}, \mathrm{NO}, \mathrm{NO}_{2}, \mathrm{NO}_{3}, \mathrm{~N}_{2} \mathrm{O}_{5}, \mathrm{HNO}_{2}$, $\mathrm{HNO}_{3}$, and $\mathrm{N}_{2} \mathrm{O}$ in the lower atmosphere of Mars. The surface reactivity coefficient $\gamma$ for $\mathrm{HNO}_{2}$ and $\mathrm{HNO}_{3}$ equals $1 \times 10^{-2}$. Dissociation of $\mathrm{N}_{2}$ is assumed to proceed through $e+\mathrm{N}_{2} \rightarrow e+\mathrm{N}\left({ }^{2} D\right)+\mathrm{N}\left({ }^{4} S\right)$. The model atmosphere used is described by Yung et al. [1977].

and nitrogen isotopes present in Mars' exosphere. Carbon atoms may also escape. Fast atoms in this case could be formed by

$$
\begin{gathered}
e+\mathrm{CO} \rightarrow e+\mathrm{C}+\mathrm{O} \\
e+\mathrm{CO}_{2} \rightarrow e+\mathrm{C}+\mathrm{O}_{2} \\
\rightarrow e+\mathrm{C}+\mathrm{O}+\mathrm{O} \\
e+\mathrm{CO}_{2}^{+} \rightarrow \mathrm{C}+\mathrm{O}_{2}
\end{gathered}
$$

or

$$
e+\mathrm{CO}^{+} \rightarrow \mathrm{C}+\mathrm{O}
$$

Diffusive separation in the Martian thermosphere will result in a preferential supply of light isotopes to the exosphere. The deficiency of the heavier isotopes at the critical level may be characterized by a parameter $R$ defined by the relation $[M c E l$ roy and Yung, 1976]

$$
R=f_{C} / f_{0}
$$

where $f_{c}$ denotes the abundance of the heavy relative to the light isotopes at the critical level and $f_{0}$ denotes the analogous quantity for the bulk atmosphere. The deficiency parameters $R$ may be readily derived as a function of the eddy diffusion coefficient $K$, taken to model effects of mixing near the turbopause. Values for $R$ as functions of $K$ are shown in Figure 13. Curve A gives the values of $R$ for ${ }^{18} \mathrm{O}$ relative to ${ }^{18} \mathrm{O}$; curve $\mathrm{B}$ gives similar information for ${ }^{16} \mathrm{~N} /{ }^{14} \mathrm{~N}$ and ${ }^{13} \mathrm{C} /{ }^{12} \mathrm{C}$. A nalysis of the Viking data [McElroy et al., 1976; Nier and McElroy, 1977] suggests a value for $K$ of about $10^{8} \mathrm{~cm}^{2} \mathrm{~s}^{-1}$.

Consider a reservoir which contains an initial concentration of gas $b(0)$ atoms $\mathrm{cm}^{-2}$, of known isotopic composition $f_{0}(0)$. The concentration of gas in the reservoir at time $t, b(t)$, will vary with time according to the equation

$$
d b / d t=-\left(\phi_{1}+\phi_{2}\right)
$$

where $\phi_{1}$ denotes the rate at which gas escapes to space $\left(\mathrm{cm}^{-2}\right.$ $\mathrm{s}^{-1}$ ), an isotopically dependent quantity as was noted above; $\phi_{2}$ defines the loss rate $\left(\mathrm{cm}^{-2} \mathrm{~s}^{-1}\right)$ for all isotopically insensitive removal processes. The time evolution of the bulk isotopic composition is given then by

$$
b d f_{0} / d t=(1-R) \phi_{1} f_{0}
$$


Consider the application of this simple model to study the time evolution of ${ }^{10} \mathrm{O}$ and ${ }^{18} \mathrm{O}$. The escape rate for $\mathrm{O}$ has a magnitude of $6 \times 10^{7}$ atoms $\mathrm{cm}^{-2} \mathrm{~s}^{-1}$, as discussed above. The additional flux $\phi_{2}$ may be used to model loss of $\mathrm{O}$ due to oxidation of surface rocks. We shall assume that ${ }^{18} \mathrm{O} /{ }^{18} \mathrm{O}$ is enriched in the present Martian atmosphere by less than $5 \%$ [Nier and McElroy, 1977] with respect to initial conditions. The manner in which the enrichment of ${ }^{18} \mathrm{O}$ should vary with respect to the initial reservoir size is illustrated in Figure 14. It is clear that Mars' atmosphere must be in contact with a reservoir containing a source of oxygen at least as large as 4.5 $\times 10^{25}$ atoms $\mathrm{cm}^{-2}$. It is probable that this reservoir reflects the presence of a relatively large concentration of atmospherically exchangeable subsurface $\mathrm{H}_{2} \mathrm{O}$ [McElroy and Yung, 1976].

Viking's measurement of isotopically enriched ${ }^{15} \mathrm{~N}$ may be used in a similar manner to place a lower bound on the initial concentration of volatile nitrogen. An enrichment of 1.62 [Nier and $M c$ Elroy, 1977] requires an initial $\mathrm{N}_{2}$ concentration of no less than $7.8 \times 10^{22}$ molecules $\mathrm{cm}^{-2}$, equivalent to a partial pressure of $1.3 \mathrm{mbar}$. The time evolution of Martian nitrogen will be sensitive to surface reactions involving $\mathrm{HNO}_{2}$ and $\mathrm{HNO}_{3}$ as described earlier. The enrichment as predicted for ${ }^{15} \mathrm{~N}$ will depend on assumptions made with regard to the magnitude of the initial source of volatile $\mathrm{N}$ and its isotopic composition, surface reactivity, and escape efficiency. Two possible models are illustrated in Figure 15 . The surface reactivity $\gamma$ (for $\mathrm{HNO}_{2}$ and $\mathrm{HNO}_{3}$ ) was taken to be $3 \times 10^{-2}$ (case A) and $1 \times 10^{-2}$ (case B). More detailed discussion of the possible range of values for $\gamma$ is given by Yung et al. [1977]. The present calculations imply an initial $\mathrm{N}_{2}$ abundance of about $1.7 \times 10^{24}$ molecules $\mathrm{cm}^{-2}$, equivalent to a partial pressure of $\mathbf{3 0}$ mbar. Considerable uncertainty is attached to this value, arising in part from our assumption that the eddy diffusion coefficient $K$ is constant in time and in part from the lack of precision in our estimate for the escape efficiency of $N$. Our analysis nonetheless provides a reasonable estimate (factor of 3 ) for the initial nitrogen abundance. One might argue that $K$ is set mainly by dynamical processes controlled by insolation and topography. Uncertainties in the escape rate (and consequently in $\gamma$ ) may be removed by suitable laboratory experimentation.

The observed enrichment of ${ }^{15} \mathrm{~N}$ may be used to place limits

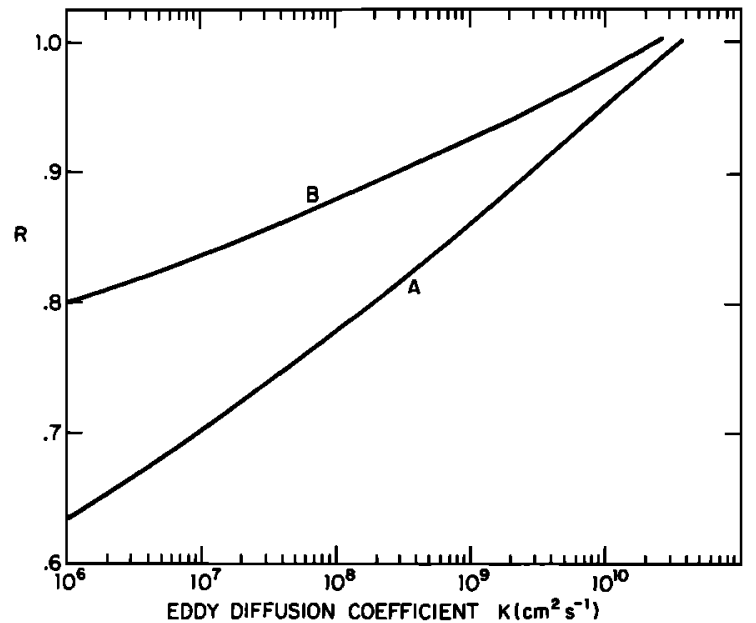

Fig. 13. Values of $R$, the deficiency parameter for the heavier isotope in the exosphere, as a function of the eddy diffusion coefficient $K$. Curve $A$ is appropriate for ${ }^{18} \mathrm{O} /{ }^{16} \mathrm{O}$. Curve $\mathrm{B}$ applies to ${ }^{16} \mathrm{~N} /{ }^{14} \mathrm{~N}$ and ${ }^{13} \mathrm{C} /{ }^{12} \mathrm{C}$.

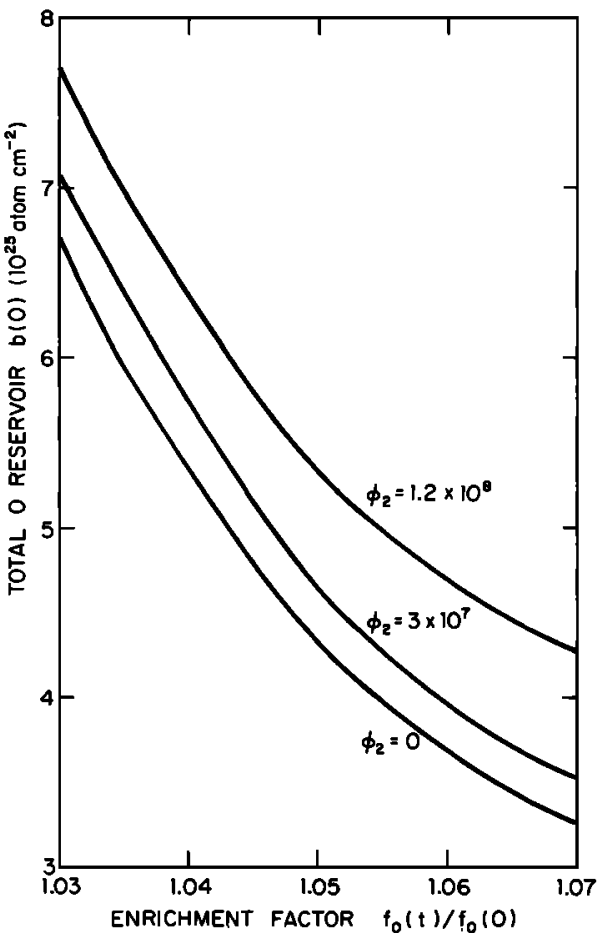

Fig. 14. Total oxygen reservoir at $t=0$ as a function of the enrichment factor $f_{0}(t) / f_{0}(0)$ at $t=4.5$ b.y. for $\phi_{2}=1.2 \times 10^{8}, 3 \times 10^{7}$, and 0 atoms $\mathrm{cm}^{-2} \mathrm{~s}^{-1}$, respectively.

on the rate at which the atmosphere may gain nitrogen because of slow, steady degassing from the interior. Here, as before, we denote the initial atmospheric abundance of nitrogen by a quantity $b(0)$ atoms $\mathrm{cm}^{-2}$. The time independent steady source

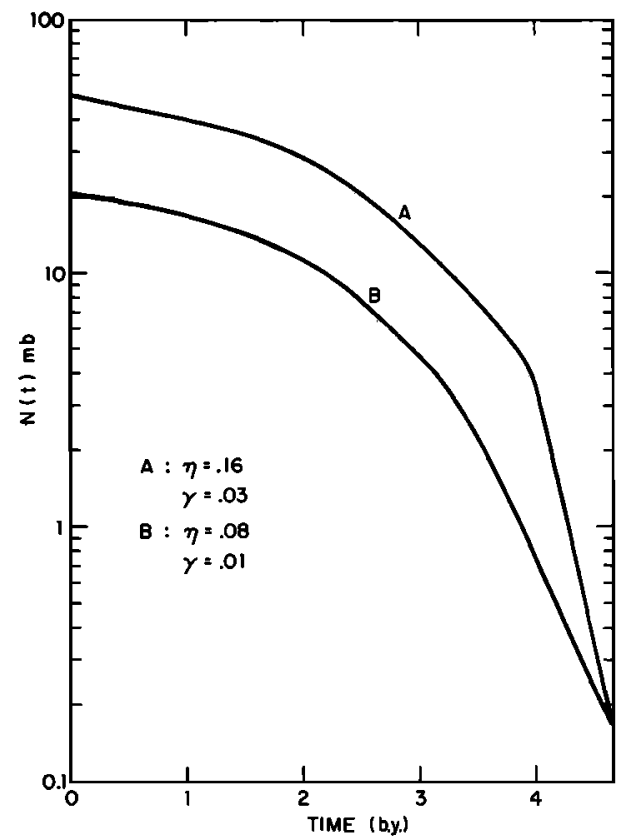

Fig. 15. Abundance of $\mathbf{N}_{2}$ (in millibars) as a function of time (in units of $10^{9}$ years). The enrichment factor at $t=4.5 \mathrm{~b}$.y. is 1.62 for both curves, in accord with measurements. For case A the escape efficiency $\eta$ for the reaction $e+\mathrm{N}_{2} \rightarrow e+\mathrm{N}+\mathrm{N}$ to produce an escaping atom is 0.16 ; the surface reactivity coefficient $\gamma$ (for $\mathrm{HNO}_{2}$ and $\mathrm{HNO}_{3}$ ) is 0.03 . The corresponding values for $\eta$ and $\gamma$ in case $\mathrm{B}$ are 0.08 and 0.01 , respectively. The eddy diffusion coefficient $K$ used in these calculations equals $1 \times 10^{8} \mathrm{~cm}^{2} \mathrm{~s}^{-1}$. This figure is adapted from McElroy et al. [1976]. 


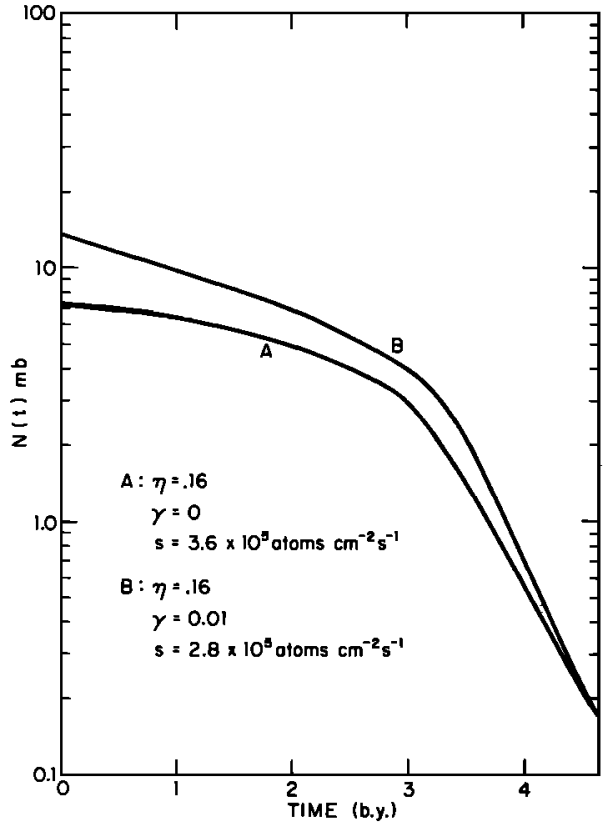

Fig. 16. Abundance of $\mathrm{N}_{2}$ as a function of time. Enrichment at $t=$ 4.5 b.y. is 1.62; escape efficiency $\eta=0.16$ for both curves. Case $A$ assumes $\gamma=0$ and $S=3.6 \times 10^{5}$ atoms $\mathrm{cm}^{-2} \mathrm{~s}^{-1}$. Case B assumes $\gamma=$ 0.01 and $S=2.8 \times 10^{5}$ atoms $\mathrm{cm}^{-2} \mathrm{~s}^{-1}$

of nitrogen is defined by a quantity $S$ atoms $\mathrm{cm}^{-2} \mathrm{~s}^{-1}$, and the abundance of atmospheric nitrogen at time $t, b(t)$, satisfies the relation

$$
d b / d t=-\left(\phi_{1}+\phi_{2}\right)+S
$$

where the various symbols have the significance discussed earlier. The time evolution of the isotopic composition is given now by

$$
b d f_{0} / d t=(1-R) \phi_{1} f_{0}-\left(f_{0}-f_{0}^{*}\right) S
$$

where $f_{0}{ }^{*}$ defines the enrichment associated with the source $S$, assumed to be equal to $f_{0}(0)$. Results for several combinations of the parameters $\phi_{2}$ and $S$ are shown in Figure 16. It is clear that $S$ cannot exceed about $4 \times 10^{5}$ atoms $\mathrm{cm}^{-2} \mathrm{~s}^{-1}$, which may be compared with the escape rate in the present atmosphere, estimated at $10^{6}$ atoms $\mathrm{cm}^{-2} \mathrm{~s}^{-1}$. The escape rate in the past depends on the instantaneous abundance of $\mathrm{N}_{2}$ and was calculated as described above. It follows that Mars must have acquired its nitrogen atmosphere early in the evolutionary history of the planet. The degassing rate for nitrogen at the present epoch must be less than the average degassing rate over the planet's history by a factor of at least 20 . One might suppose that a similar conversion should hold for other volatiles with the exception of radiogenic gases such as ${ }^{40} \mathrm{Ar}$.

It may be of interest now to examine the possibility of a common origin for the volatile budgets of Mars and earth. A number of papers have appeared in the recent literature attributing planetary volatiles to different classes of chondrites [Turekian and Clark, 1975; Owen et al., 1976; Rasool and Le Sergeant, 1977]. Information for earth is summarized in Table 3. An acceptable model for Mars requires either selective degassing of nitrogen relative to noble gases or a volatile composition for Mars significantly different from that indicated for earth in Table 3.

Suppose that the initial volatile compositions of earth and Mars were similar. A difference in the formation temperatures of the two planets could lead to differential rates for release of $\mathrm{H}_{2} \mathrm{O}, \mathrm{CO}_{2}, \mathrm{~N}_{2},{ }^{36} \mathrm{Ar}, \mathrm{Kr}$, and Xe. Laboratory experiments [Zahringer, 1962; Heymann, 1971] suggest that noble gases in meteorites are released at relatively elevated temperatures, above about $900^{\circ} \mathrm{K}$ for ${ }^{3 e} \mathrm{Ar}, \mathrm{Kr}$, and $\mathrm{Xe}$. Suppose that nitrogen were present in more volatile forms, either as interstitial atoms or molecules or as components of the organic complexes identified in carbonaceous chondrites [Moore, 1971]. In this case, Mars could have acquired an early atmosphere rich in $\mathrm{H}_{2} \mathrm{O}, \mathrm{CO}_{2}$, and $\mathrm{N}_{2}$. Thermal constraints would have limited the gas phase concentrations of $\mathrm{H}_{2} \mathrm{O}$ and $\mathrm{CO}_{2}$. Molecular nitrogen might have accumulated as the major constituent of the atmosphere, while $\mathrm{H}_{2} \mathrm{O}$ and $\mathrm{CO}_{2}$ would have been stored in condensed form in near-surface regions of the planet. An illustrative model for this situation, case $A$, is included in Table 3. We assume here that most of the noble gases remain trapped by the bulk planet. ${ }^{10} \mathrm{Ar}$ is released at a rate $\left(\mathrm{g} / \mathrm{g} \mathrm{s}^{-1}\right)$ less than that appropriate for earth by a factor of 20 . The smaller source for ${ }^{40} \mathrm{Ar}$ may reflect either a smaller concentration of crustal ${ }^{40} \mathrm{~K}$ on Mars or a slower degassing rate or both. Note that with this model the atmosphere acquires its argon and nitrogen at quite distinct phases of planetary evolution.

\begin{tabular}{|c|c|c|c|c|c|c|c|c|}
\hline & $\mathrm{H}_{2} \mathrm{O}$ & $\mathrm{C}$ & $\mathbf{N}$ & $\mathrm{Ne}$ & ${ }^{30} \mathrm{Ar}$ & ${ }^{40} \mathrm{Ar}$ & $\mathrm{Kr}$ & $\mathrm{Xe}$ \\
\hline Earth* & $2.8 \times 10^{-4}$ & $1.7 \times 10^{-6}$ & $7.7 \times 10^{-7}$ & $1.1 \times 10^{-11}$ & $3.5 \times 10^{-11}$ & $1.1 \times 10^{-8}$ & $2.6 \times 10^{-12}$ & $3.6 \times 10^{-1}$ \\
\hline $\begin{array}{l}\text { Martian atmosphere, } \\
\text { present }{ }^{\dagger} \\
\text { Martian atmosphere and } \\
\text { crust } \ddagger\end{array}$ & $\sim 2.2 \times 10^{-12}$ & $1.1 \times 10^{-8}$ & $6.2 \times 10^{-10}$ & $<1.8 \times 10^{-13}$ & $1.9 \times 10^{1 \mathrm{~s}}$ & $5.7 \times 10^{-10}$ & $2.2 \times 10^{-11}$ & $3.5 \times 10^{-1}$ \\
\hline \multicolumn{9}{|l|}{ Case A } \\
\hline Initial & $3.0 \times 10^{-5}$ & $2.9 \times 10^{-8}$ & $1.3 \times 10^{-7}$ & small & small & small & small & small \\
\hline \multicolumn{6}{|l|}{ Case B } & $5.7 \times 10^{-10}$ & $2.7 \times 10^{-14}$ & $3.5 \times 10^{-15}$ \\
\hline Initial & $3.0 \times 10^{-5}$ & $2.9 \times 10^{-8}$ & small & $6.0 \times 10^{-14}$ & $5.9 \times 10^{-12}$ & small & $2.9 \times 10^{-13}$ & $1.7 \times 10^{-12}$ \\
\hline Intermediate & $3.0 \times 10^{-5}$ & $2.9 \times 10^{-6}$ & $1.3 \times 10^{-7}$ & small & small & small & small & small \\
\hline Present & $2.9 \times 10^{-5}$ & $2.9 \times 10^{-6}$ & $2.4 \times 10^{-8}$ & $6.0 \times 10^{-14}$ & $1.9 \times 10^{-13}$ & $5.7 \times 10^{-10}$ & $2.7 \times 10^{-14}$ & $3.5 \times 10^{-15}$ \\
\hline \multicolumn{9}{|l|}{ Case C } \\
\hline Initial & $3.0 \times 10^{-5}$ & $2.9 \times 10^{-6}$ & $1.3 \times 10^{-7}$ & $6.0 \times 10^{-14}$ & $1.9 \times 10^{-13}$ & small & $2.7 \times 10^{-14}$ & $3.5 \times 10^{-15}$ \\
\hline Present & $2.9 \times 10^{-5}$ & $2.9 \times 10^{-8}$ & $2.4 \times 10^{-8}$ & $6.0 \times 10^{-14}$ & $1.9 \times 10^{-1 s}$ & $5.7 \times 10^{-10}$ & $2.7 \times 10^{-14}$ & $3.5 \times 10^{-15}$ \\
\hline
\end{tabular}

TABLE 3. Models for the Evolution of Martian Volatiles

Units are grams of volatile per gram of total planetary material.

*From McElroy [1976] and Turekian and Clark [1975].

†From Nier and McElroy [1977] and Owen et al. [1976].

$\ddagger D$ iscussed in this paper. 
The nitrogen concentration included in the table reflects our best estimate based on studies of escape as constrained to satisfy the Viking ${ }^{15} \mathrm{~N}$ observation. The $\mathrm{H}_{2} \mathrm{O}$ and $\mathrm{CO}_{2}$ concentrations are defined by scaling the terrestrial abundances listed in the first row of the table. An $\mathrm{H}_{2} \mathrm{O}$ concentration of magnitude $4.7 \times 10^{-5} \mathrm{~g} / \mathrm{g}$ would require a planet-wide ice layer of thickness $200 \mathrm{~m}$. Alternatively, it could be accommodated by a crustal material containing $3 \% \mathrm{H}_{2} \mathrm{O}$ if this crust had an average thickness of $3 \mathrm{~km}$. If one were to adopt the lower bound as discussed earlier for the initial nitrogen concentration, the abundances of $\mathrm{H}_{2} \mathrm{O}, \mathrm{CO}_{2}$, and $\mathrm{N}_{2}$ could be reduced by a factor of 15 .

Case B considers a rather different model in which we assume that nitrogen in the early Martian system may in fact have been less volatile than ${ }^{80} \mathrm{Ar}, \mathrm{Kr}$, and $\mathrm{Xe}$. This situation could have arisen if nitrogen had been present mainly in stable compounds such as sinoite $\left(\mathrm{Si}_{2} \mathrm{~N}_{2} \mathrm{O}\right)$ or osbornite ( $\left.\mathrm{TiN}\right)$, as appears to be the case for enstatite chondrites and achondrites [C. A. Anderson et al., 1964; K. Keil and C. A. Anderson, 1965; Bannister, 1941]. Then devolatilization of the early planet might have favored release of $\mathrm{H}_{2} \mathrm{O}, \mathrm{CO}_{2}$, and noble gases, nitrogen being released subsequently during the period when the planet underwent major differentiation. The concentrations of $\mathrm{H}_{2} \mathrm{O}$ and $\mathrm{CO}_{2}$ in the primitive atmosphere would be limited for case B, as for case A, by thermal constraints, and the planet would have developed an initial atmosphere rich in ${ }^{38} \mathrm{Ar}, \mathrm{Kr}$, and $\mathrm{Xe}$. Noble gases in this system would be exposed directly to the solar wind. Under present solar wind conditions a magnetic field of $\sim 20 \gamma$ would be required to shield the upper atmospherc of Mars from such an interaction. It is clear that Mars does not possess a magnetic field of this magnitude today, nor is it likely that it ever did. The number of particles that can be swept away by the solar wind is limited by the rate of photo-ionization and by mass loading of the solar wind itself. It may be shown [Michel, 1971] that the latter factor determines the maximum escape rate. Michel [1971] gives a largely model independent formula for the mass loss rate,

$$
d M / d t=0.86\left(T / 10^{3}\right)(40 / m) \mathrm{g} / \mathrm{s}
$$

where $d M / d t$ denotes the total mass loss rate expressed in grams per second, $T$ denotes the temperature of the exosphere in degrees Kelvin, and $m$ denotes the molecular weight of the escaping gas. Applying Michel's simple formula, we can show that the time required for about $1 \times 10^{20}$ atoms $\mathrm{cm}^{-2}$ of ${ }^{36} \mathrm{Ar}$ to escape is less than 0.5 b.y., and similarly short times would be associated with the removal of $\mathrm{Kr}$ and $\mathrm{Xe}$. Light noble gases would be stripped first, followed by the heavier components. There would be an associated loss of $\mathrm{CO}_{2}$ and $\mathrm{H}_{2} \mathrm{O}$, whose extent would depend fairly critically on the duration of this hypothetical early evolutionary phase. The time interval associated with this phase would be relatively brief if the early sun were more active than is assumed here. Properties of case B are summarized in Table 3.

Case $C$ in Table 3 summarizes a model in which we relax the requirement that volatiles on Mars and earth should have similar compositions. We assume here that all volatile compounds may be released with equal efficiency. The nitrogen model requires that the planet undergo a period of rapid initial degassing. The early atmosphere should be rich in $\mathbf{N}_{2}$ and noble gases and would be protected from the scavenging effects of the solar wind. Thus we must assume that Mars was assembled from material rich in $\mathrm{N}_{2}$ relative to noble gases, and the various parameters in the table reflect this view. As was noted earlier, the $\mathrm{H}_{2} \mathrm{O}$ concentration for all models must ex- ceed $5 \times 10^{-6} \mathrm{~g} / \mathrm{g}$. The concentrations for $\mathrm{CO}_{2}$ and $\mathrm{H}_{2} \mathrm{O}$ in case $\mathrm{C}$ were obtained by scaling from $\mathrm{N}_{2}$ by using terrestrial ratios for $\mathrm{H}_{2} \mathrm{O}: \mathrm{CO}_{2}: \mathrm{N}_{2}$.

Model $\mathrm{C}$ seems the most plausible. It avoids the ad hoc assumption of time differential degassing for $\mathrm{N}_{2}$ and noble gases implicit in models A and B. Differences between Mars and earth might be attributed to relatively more extensive degassing in the latter case, degassing extending to greater depths where the material may be deficient in low-temperature condensates. It is interesting to note in this context that the nitrogen to noble gas ratios inferred here for the primitive Mars are similar to values found for a wide class of meteorites [Gibson, 1969; Eugster et al., 1969; Mazor et al., 1970; Heymann, 1971; Van Schmus, 1974]. It suggests that scaling of noble gas abundances from earth to other planets may be hazardous. Measurements of noble gas abundances in the atmosphere of Venus, scheduled for the upcoming Pioneer probe, should provide additional insights. Major uncertainties remain in the interim.

\section{SUMmary}

Viking results, in combination with earlier data from Mariner $4,6,7$, and 9 , have been used to develop a relatively comprehensive model of Martian aeronomy. Escape of $\mathrm{H}, \mathrm{O}$, and $\mathbf{N}$ played an important role in the evolution of Mars' atmosphere. It is not possible, however, to identify a unique combination of parameters to define the initial inventory of Martian volatiles, though the planet appears to have undergone a period of rapid early degassing, at least for $\mathrm{N}_{2}$. Measurements of noble gases in the present Martian environment are especially puzzling. The possibility that the composition of Mars' atmosphere may have been influenced by interactions with the solar wind over the early stages of planetary evolution should not be ignored. The absence of a significant Martian magnetic field may have contributed to differences in the evolutionary paths of Mars and earth, a possibility which could be illuminated further by mass spectrometric measurements on the scheduled Pioneer mission to Venus.

Acknowledgments. This work was supported by the National Aeronautics and Space Administration under grant NAS-1-10492 and by the National Science Foundation under grant NSF-ATM75-22723, both to Harvard University. We are indebted to E. Anders, T. Owen, and $\mathrm{S}$. Wofsy for illuminating discussions.

\section{ReFERENCES}

Anderson, C. A., K. Keil, and B. Mason, Silicon oxynitride: A meteoritic mineral, Science, 146, 256-257, 1964.

Anderson, D. E., and C. W. Hord, Mariner 6 and 7 ultraviolet spectrometer experiment: Analysis of hydrogen Lyman $\alpha$ data, $J$. Geophys. Res., 76, 6666, 1971.

Bannister, F. A., Osbornite, meteoritic titanium nitride, Mineral. Mag., 26, 36-44, 1941.

Barth, C. A., A. I. Stewart, C. W. Hord, and A. L. Lane, Mariner 9 ultraviolet spectrometer experiment: Mars airglow spectroscopy and variations in Lyman $\alpha$, Icarus, 17, 457, 1972.

Conrath, B. J., Thermal structure of the Martian atmosphere during the dissipation of the dust storm of 1971, Icarus, 24, 36, 1975.

Eugster, O., P. Eberhardt, and J. Geiss, Isotopic analyses of krypton and xenon in fourteen stone meteorites, J. Geophys. Res., 74, 3874-3896, 1969.

Fehsenfeld, F. C., D. B. Dunkin, and E. E. Ferguson, Rate constants for the reaction of $\mathrm{CO}_{2}{ }^{+}$with $\mathrm{O}, \mathrm{O}_{2}$ and $\mathrm{NO}^{-}, \mathrm{N}_{2}{ }^{+}$with $\mathrm{O}$ and $\mathrm{NO}$, and $\mathrm{O}_{2}{ }^{+}$with $\mathrm{NO}$, Planet. Space Sci., 18, 1267, 1970.

Fjeldbo, G. A., A. Kliore, and B. Seidel, The Mariner 1969 occultation measurements of the upper atmosphere of Mars, Radio Sci., 5, 381-386, 1970 .

Gibson, E. K., Ph.D. thesis, Ariz. State Univ., Tempe, 1969. 
Gierasch, P. J., and R. M. Goody, The effect of dust on the temperature of the Martian atmosphere, J. Atmos. Sci., 29, 400, 1972.

Heymann, D., The inert gases: $\mathrm{He}^{(2)}, \mathrm{Ne}^{(10)}, \mathrm{Ar}^{(18)}, \mathrm{Kr}^{(38)}$ and $\mathrm{Xe}^{(64)}$, in Handbook of Elemental Abundances in Meteorites, edited by B. Mason, chap. 2, pp. 29-66, Gordon and Breach, New York, 1971.

Hinteregger, H. E., The extreme ultraviolet solar spectrum and its variation during a solar cycle, Ann. Geophys., 26, 547-554, 1970.

Hinteregger, H. E., EUV fluxes in the solar spectrum below $2000 \AA$, $J$. Atmos. Terr. Phys., 38, 791-806, 1976.

Huguenin, R. L., Photostimulated oxidation of magnetite, 1, Kinetics and alteration phase identification, J. Geophys. Res., 78, 848I, $1973 a$.

Huguenin, R. L., Photostimulated oxidation of magnetite, 2, Mechanism, J. Geophys. Res., 78, 8495, $1973 b$.

Huguenin, R. L., The formation of goethite and hydrated clay minerals on Mars, J. Geophys. Res., 79, 3895, 1974.

Huguenin, R. L., Surface oxidation: A major sink for water on Mars, Science, 192, 138, 1976.

Izakov, M. N., On the temperature of the Martian upper atmosphere (in Russian), Kosm. Issled., 11, 761, 1973.

Keil, K., and C. A. Anderson, Occurrences of sinoite in meteorites, Nature, 207, 745, 1965.

Kliore, A. J., Radio occultation exploration of Mars, Exploration of the Planetary System, IAU Rep. 65, p. 295, Int. Astron. Union, 1974.

Kliore, A. J., D. L. Cain, G. S. Levy, R. Eshleman, G. A. Fjeldbo, and D. Drake, Occultation experiment: Results of the first direct measurement of Mars' atmosphere and ionosphere, Science, 149, 1243, 1965.

Kliore, A. J., G. Fjeldbo, B. L. Seidel, and S. I. Rasool, Mariner 6 and 7: Radio occultation measurements of the atmosphere of Mars, Science, 166, 1393, 1969

Kliore, A. J., D. L. Cain, G. Fjeldbo, B. L. Seidel, and M. J. Sykes, The atmosphere of Mars from Mariner 9 radio occultation measurements, Icarus, 17, 484, 1972.

Kliore, A. J., G. Fjeldbo, B. L. Seidel, M. J. Sykes, and P. M. Woiceshyn, $S$ band radio occultation measurements of the atmosphere and topography of Mars with Mariner 9: Extended mission coverage of polar and intermediate latitudes, J. Geophys. Res., 78 , 4331-4351, 1973.

Kong, T. Y., and M. B. McElroy, Photochemistry of the Martian atmosphere, Icarus, in press, $1977 a$.

Kong, T. Y., and M. B. McElroy, The global distribution of $O_{s}$ on Mars, Planet. Space Sci., in press, $1977 b$.

Liu, S., and T. M. Donahue, The regulation of hydrogen and oxygen escape from Mars, Icarus, 28, 231-246, 1976.

Mazor, E., D. Heymann, and E. Anders, Noble gases in carbonaceous chondrites, Geochim. Cosmochim. Acta, 34, 781-824, 1970.

McElroy, M. B., Mars: An evolving atmosphere, Science, 175, 443. 1972.

McElroy, M. B., Chemical processes in the solar system: A kinetic perspective, in International Review of Science, vol. 9, Chemical Kinetics, edited by D. R. Herschbach, pp. 127-211, Butterworths, Boston, 1976.

McElroy, M. B., and T. M. Donahue, Stability of the Martian atmosphere, Science, 177, 986-988, 1972.

McElroy, M. B., and T. Y. Kong, Oxidation of the Martian surface:
Constraints due to chemical processes in the atmosphere, Geophys. Res. Lett., 3, 569, 1976.

McElroy, M. B., and J. C. McConnell, Dissociation of $\mathrm{CO}_{2}$ in the Martian atmosphere, J. Atmos. Sci., 28, 879, 1971.

McElroy, M. B., and Y. L. Yung, Oxygen isotopes in the Martian atmosphere: Implications for the evolution of volatiles, Planet. Space Sci., 24, 1107-1113, 1976.

McElroy, M. B., T. Y. Kong, Y. L. Yung, and A. O. Nier, Composition and structure of the Martian upper atmosphere: Analysis of results from Viking, Science, 194, 1295-1298, 1976.

Michel, F. C., Solar-wind-induced mass loss from magnetic field free planets, Planet. Space Sci., 19, 1580, 1971.

Moore, C. B., Nitrogen, in Handbook of Elemental Abundances in Meteorites, edited by B. Mason, chap. 7, pp. 93-98, Gordon and Breach, New York, 1971.

Nier, A. O., and M. B. McElroy, Structure of the neutral upper atmosphere of Mars: Results from Viking 1 and Viking 2, Science, $194,1298-1300,1976$

Nier, A. O., and M. B. McElroy, Composition and structure of Mars' upper atmosphere: Results from the neutral mass spectrometers on Viking I and 2, J. Geophys. Res., 82, this issue, 1977.

Nier, A. O., M. B. McElroy, and Y. L. Yung, Isotopic composition of the Martian atmosphere, Science, 194,68-70, 1976a.

Nier, A. O., W. B. Hanson, A. Seiff, M. B. McElroy, N. W. Spencer, R. J. Duckett, T. C. D. Knight, and W. S. Cook, Composition and structure of the Martian atmosphere: Preliminary results from Viking 1, Science, 193, 786-788, $1976 b$.

Owen, T., and K. Biemann, Composition of the atmosphere at the surface of Mars: Detection of $\mathrm{Ar}^{38}$ and preliminary analysis, Science, $193,801-803,1976$.

Owen, T., K. Biemann, D. R. Rushneck, J. E. Biller, D. W. Howarth, and A. L. La Fleur, The atmosphere of Mars: Detection of krypton and xenon, Science, 194, 1293, 1976.

Parkinson, T. M., and D. M. Hunten, Spectroscopy and aeronomy of $\mathrm{O}_{2}$ on Mars, J. Atmos. Sci., 29, 1380, 1972.

Rasool, S. I., and L. Le Sergeant, Volatile outgassing from earth and Mars: Implications of Viking results, Nature, in press, 1977.

Stewart, A. I., Mariner 6 and 7 ultraviolet spectrometer experiment: Implications of the $\mathrm{CO}_{2}{ }^{+}, \mathrm{CO}$, and $\mathrm{O}$ airglow, J. Geophys. Res., 77, 54, 1972

Stewart, A. I., C. A. Barth, C. W. Hord, and A. L. Lane, Mariner 9 ultraviolet spectrometer experiment: Structure of Mars' upper atmosphere, Icarus, 17, 469-474, 1972.

Turekian, K. K., and S. P. Clark, The non-homogeneous accumulation model for terrestrial planet formation and the consequence for the atmosphere of Venus, J. Atmos. Sci., 32, 1257, 1975.

Van Schmus, H., Chemical and detrographic correlations among carbonaceous chondrites, Geochim. Cosmochim. Acta, 38, 47-64, 1974.

Yung, Y. L., D. F. Strobel, T. Y. Kong, and M. B. McElroy, Photochemistry of nitrogen in the Martian atmosphere, Icarus, 30 , $26,1977$.

Zahringer, J., Ueber die Uredelgase in den Achondriten kapoeta und staroe pesjanoe, Geochim. Cosmochim. Acta, 26, 665-680, 1962.

(Received April 21, 1977:

revised June 8, 1977;

accepted June 8, 1977.) 